\title{
Impact of Global Climate Change on the European Barley Market Requires Novel Multi-Method Approaches to Preserve Crop Quality and Authenticity
}

\author{
Stefan G. Bindereif ${ }^{1}$, Felix Rüll ${ }^{2}$, Peter Kolb ${ }^{2}$, Lucas Köberle ${ }^{3}$, Holger Willms ${ }^{4}$, Simon Steidele ${ }^{2}$, \\ Stephan Schwarzinger ${ }^{2, *}$ and Gerhard Gebauer ${ }^{1, *} \mathbb{D}$ \\ 1 BayCEER - Laboratory of Isotope Biogeochemistry, University of Bayreuth, Universitätsstraße 30, \\ 95447 Bayreuth, Germany; stefan.bindereif@uni-bayreuth.de \\ 2 NBNC-North Bavarian NMR Centre, University of Bayreuth, Universitätsstraße 30, \\ 95447 Bayreuth, Germany; Felix.Ruell@uni-bayreuth.de (F.R.); peter.kolb.mail@googlemail.com (P.K.); \\ simon-steidele@outlook.de (S.S.) \\ 3 ALNuMed GmbH, Gottlieb-Keim Straße 60, 95448 Bayreuth, Germany; lucasausberg@gmx.de \\ 4 IREKS GmbH, Lichtenfelser Straße 20, 95326 Kulmbach, Germany; holger.willms@ireks.com \\ * Correspondence: s.schwarzinger@uni-bayreuth.de (S.S.); gerhard.gebauer@uni-bayreuth.de (G.G.); \\ Tel.: +49-(0)-9-2155-2046 (S.S.); +49-(0)-9-2155-2060 (G.G.)
}

Citation: Bindereif, S.G.; Rüll, F.; Kolb, P.; Köberle, L.; Willms, H.; Steidele, S.; Schwarzinger, S.; Gebauer, G. Impact of Global Climate Change on the European Barley Market Requires Novel Multi-Method Approaches to Preserve Crop Quality and Authenticity. Foods 2021, 10, 1592. https://doi.org/10.3390/foods 10071592

Received: 27 May 2021

Accepted: 6 July 2021

Published: 8 July 2021

Publisher's Note: MDPI stays neutral with regard to jurisdictional claims in published maps and institutional affiliations.

Copyright: (c) 2021 by the authors. Licensee MDPI, Basel, Switzerland This article is an open access article distributed under the terms and conditions of the Creative Commons Attribution (CC BY) license (https:// creativecommons.org/licenses/by/ $4.0 /)$
Abstract: Most recently in 2018 and 2019, large parts of Europe were affected by periods of massive drought. Resulting losses in cereal yield pose a major risk to the global supply of barley, as more than $60 \%$ of global production is based in Europe. Despite the arising price fluctuations on the cereal market, authenticity of the crop must be ensured, which includes correct declaration of harvest years. Here, we show a novel approach that allows such differentiation for spring barley samples, which takes advantage of the chemical changes caused by the extreme drought. Samples from 2018 were successfully differentiated from those of 2017 by analysis of changes in near-infrared spectra, enrichment in the isotope ${ }^{13} \mathrm{C}$, and strong accumulation of the plant-physiological marker betaine. We demonstrate that through consideration of multiple modern analysis techniques, not only can fraudulent labelling be prevented, but indispensable knowledge on the drought tolerance of crops can be obtained.

Keywords: barley; stable isotopes; proton nuclear magnetic resonance; Fourier transform nearinfrared spectroscopy; drought; climate change; Europe; Germany; multi-method approach; beer

\section{Introduction}

Recent climate changes in Europe are characterized by frequent and severe weather extremes, which pose a major threat to agricultural production and are predicted to increase in the near future [1,2]. Particularly during the last two decades, most parts of Europe were impacted by record-breaking droughts leading to losses in both crop yield and quality. Global warming poses a serious challenge to the global barley (Hordeum vulgare L.) supply, as more than $60 \%$ of the world's barley production is provided by Europe, most of it grown under rainfed conditions [3]. This crop is mainly used as malting barley for the production of alcoholic beverages and for feeding animals. European beverage producers typically use spring barley for malting due to its low protein content and thus more fermentable portion of sugar. However, spring barley has its most sensitive periods during flowering and grain filling around the summer months, hence there is a high risk of yield loss and crop failure in extremely dry years [4]. In 2018, Germany, the largest producer of spring barley in Europe, experienced its warmest year ever recorded in the 138 years of modern temperature records, ultimately resulting in the lowest cereal yield since 1994 and creating existence-threatening conditions for many farmers across the country [5]. Subsequently, farmers were forced to mix low-grade spring barley batches and marketable grains from previous harvest years 
to meet the quality requirements of the customers. However, malthouses often refuse to accept deliveries of blends from two harvest years, consequently the product can only be offered as significantly less profitable feed barley [6]. Such stages of emergency increase the risk of economically motivated food fraud. The likelihood of these scenarios gains in importance when considering a recently published model by Xie et al., who found that the effects of concurrent drought extremes will cause a large decrease in global barley supply under forecasted climate conditions [7]. To preserve transparency in such difficult periods, the development of a method that is capable of classifying spring barley by harvest year is indispensable. Here, we assess the potential of distinguishing spring barley grain samples according to the very different harvest years 2017 and 2018. We looked at two varieties, namely the modern and high-yielding cultivar 'Quench' (H. vulgare L. cv. Quench, year of approval: 2006) and the comparatively old cultivar 'Steffi' (H. vulgare L. cv. Steffi, year of approval: 1989). As results produced by a single analytical method often do not provide enough information for an adequate evaluation, we have developed a novel methodology using fused data from stable isotope analysis (IRMS) and chemical fingerprints provided by Fourier-transform infrared spectroscopy (FT-NIR). Furthermore, metabolite profiles produced by proton nuclear magnetic resonance $\left({ }^{1} \mathrm{H}-\mathrm{NMR}\right)$ were applied to substantiate the findings through identification of stress-related plant physiological parameters. For the present work, we hypothesize that the severe drought events of 2018 created systematic variability in the chemical makeup of barley grains that, when evaluated by our multimethodological approach, should allow effective separation from samples of 2017. Based on previous works found in literature, we further hypothesize that the older barley cultivar 'Steffi', though less yielding, should be more drought-tolerant than the modern cultivar 'Quench'.

\section{Materials and Methods}

\subsection{Origin and Storage of the Spring Barley Samples}

Eighty-six spring barley samples of two different varieties (H. vulgare L. cv. Quench; H. vulgare L. cv. Steffi) and from two consecutive harvest years (Quench, $\mathrm{n}_{2017}=19, \mathrm{n}_{2018}$ $=20$ and Steffi, $\mathrm{n}_{2017}=22, \mathrm{n}_{2018}=25$ ) have been provided by IREKS GmbH (Kulmbach, Germany). As the focus of this study was put on describing the effects of years with extreme drought, we were provided with barley grains grown under real conventional farming conditions rather than controlled field experiments. All plants were cultivated in the same region by an agricultural cooperative of the district Soemmerda (Thuringia, Germany) on loamy soil at $140 \mathrm{~m}$ elevation to eliminate geographic effects. Samples were received as whole grains and stored in vacuum-sealed bags at room temperature until further processing.

\subsection{Weather at the Sampling Site}

Weather data were retrieved from the Climate Data Center of the German Meteorological Service [8]. The De Martonne aridity index $\left(\mathrm{I}_{\mathrm{DM}}\right)$ was used as an indicator of drought, which is calculated according to the following equation:

$$
\mathrm{I}_{\mathrm{DM}}=\mathrm{RR} /(\mathrm{TM}+10)
$$

where $\mathrm{RR}$ is the mean annual precipitation in $\mathrm{mm}$ and $\mathrm{TM}$ is the mean air temperature in ${ }^{\circ} \mathrm{C}$ [9]. I $\mathrm{DM}_{\mathrm{DM}}$ values below 30 correspond to a humid to Mediterranean habitat, while regions with $\mathrm{I}_{\mathrm{DM}}$ values below 20 are characterized by semi-dry to dry conditions.

\subsection{Isotope-Ratio Mass Spectrometry (IRMS)}

For measurement of natural isotope abundances of the elements $\mathrm{C}, \mathrm{N}$, and $\mathrm{O}$, around $4 \mathrm{~g}$ of grains were ground to wholemeal flour in a ball mill (MM400, Retsch GmbH, Haan, Germany) at $30 \mathrm{~Hz}$ for $2 \mathrm{~min}$. The sample material was dried in a drying oven at $105^{\circ} \mathrm{C}$ to constant weight and stored in a desiccator until analysis. For carbon and nitrogen measurements, $2.8-3.5 \mathrm{mg}$ of the powder was weighed into tin capsules, while for oxygen 
measurements $0.5-1 \mathrm{mg}$ was weighed into silver capsules using a microbalance (CPA2P, Sartorius, Göttingen, Germany).

Carbon and nitrogen stable isotope ratios were measured using an elemental analyzer (NA 1108, Carlo Erba Instruments, Milan, Italy) coupled to a continuous flow isotope-ratio mass spectrometer (delta S, Finnigan MAT, Bremen, Germany) via a ConFlo III opensplit interface (Thermo Fisher Scientific, Bremen, Germany) as described by Bidartondo, Burghardt, Gebauer, Bruns, \& Read [10]. Oxygen stable isotope ratios were analyzed with thermal conversion through pyrolysis (HTO, HEKAtech, Wegberg, Germany) coupled to a continuous flow isotope-ratio mass spectrometer (delta $\mathrm{V}$ advantage, Thermo Fisher Scientific) via a ConFlo IV open-split interface (Thermo Fisher Scientific) as described by Gebauer, Preiss, \& Gebauer [11]. Isotope abundances are given in $\delta$ values, calculated according to the following equation:

$$
\delta^{13} \mathrm{C}, \delta^{15} \mathrm{~N} \text {, or } \delta^{18} \mathrm{O}=\left(\mathrm{R}_{\text {sample }} / \mathrm{R}_{\text {standard }}-1\right) \times 1000(\%)
$$

where $R_{\text {sample }}$ and $R_{\text {standard }}$ are the ratios of heavy to light isotope of the samples and the respective standard. This so called "delta notation" is used to express the difference between the isotope-number ratio of an unknown sample and an internationally agreed zero-point with known isotopic composition. Nowadays, it is commonly used in many fields of isotope research, as it enables a more convenient and accurate expression of small differences in isotope-number ratios that are usually in the order of $10^{-3}$ or smaller. The standard gases (Riessner-Gase, Lichtenfels, Germany) were calibrated with respect to international standards $\left(\mathrm{CO}_{2}\right.$ vs. V-PDB, $\mathrm{N}_{2}$ vs. $\mathrm{N}_{2}$ in air, $\mathrm{CO}$ vs. V-SMOW) with the reference substances IAEA-CH-6, IAEA-CO-8 and NBS 18 for the C isotopes, N1 and N2 for the $\mathrm{N}$ isotopes and IAEA601 and IAEA602 for the $\mathrm{O}$ isotopes, all provided by the IAEA (International Atomic Energy Agency, Vienna, Austria). Measurements of the laboratory standard acetanilide were routinely performed to control the reproducibility of $\mathrm{C}$ and $\mathrm{N}$ isotope abundance analysis [12]. Acetanilide was monitored with variable sample weight at least six times per batch of 50 samples. For oxygen isotope abundance measurements, benzoic acid was analyzed with variable sample weight at least six times within each run of 40 samples. The uncertainty of measurements was always below $0.2 \%$ for $\delta^{13} \mathrm{C}, \delta^{15} \mathrm{~N}$ and $0.6 \%$ for $\delta^{18} \mathrm{O}$. Data evaluation was performed in the software ISODAT (Version 2.0, Thermo Fisher Scientific).

\subsection{Fourier-Transform Near-Infrared Spectroscopy (FT-NIR)}

FT-NIR measurements were performed on a Bruker MPA spectrometer (Bruker Optik $\mathrm{GmbH}$, Ettlingen, Germany) equipped with an interferometer, an integrating sphere for diffused reflection and a lead sulfide ( $\mathrm{PbS}$ ) detector. The sample cup was filled to the brim with whole grains and placed on a sample rotator. Spectra were recorded in triplicates using 64 scans in the range of 12,500 to $3600 \mathrm{~cm}^{-1}$ at a resolution of $16 \mathrm{~cm}^{-1}$. Data were collected and preprocessed applying baseline correction using the concave rubber-band method with 10 iterations on 64 baseline points in OPUS (Bruker Optik GmbH). Analysis of FT-NIR spectra was limited to the range between 11,000 to $4000 \mathrm{~cm}^{-1}$, and therefore excluded the flanking regions that display a strongly reduced signal-to-noise ratio.

\subsection{Proton Nuclear Magnetic Resonance $\left({ }^{1} H-N M R\right)$}

For ${ }^{1} \mathrm{H}-\mathrm{NMR}$ measurements, grains were ground to wholemeal flour in a ball mill (MM400, Retsch $\mathrm{GmbH}$ ) at $30 \mathrm{~Hz}$ for $2 \mathrm{~min} .50 \mathrm{mg}$ of wholemeal flour were weighed in a $2 \mathrm{~mL}$ reaction tube (Carl Roth $\mathrm{GmbH}$, Karlsruhe, Germany) and $2 \mathrm{~mL}$ of HPLC-grade water was added. The sample was extracted for $2 \mathrm{~h}$ in an overhead shaker (Tube Revolver D-6050, neoLab Migge GmbH, Heidelberg, Germany) at $40 \mathrm{rpm}$ before centrifugation for 45 min at 13,300 rpm (MIKRO 185, Andreas Hettich GmbH, Tuttlingen, Germany). $900 \mu \mathrm{L}$ of the supernatant was transferred in a $2 \mathrm{~mL}$ reaction tube (Carl Roth $\mathrm{GmbH}$ ) and $100 \mu \mathrm{L}$ of buffer was added [13]. The $\mathrm{pH}$ was adjusted to $3.10( \pm 0.02)$ using an automated titration 
system (BTpH Unit, Bruker BioSpin, Rheinstetten, Germany). The sample was centrifuged again for $45 \mathrm{~min}$ at 13,300 rpm (Andreas Hettich $\mathrm{GmbH}$ ) and $600 \mu \mathrm{L}$ of the supernatant was transferred in a $5 \mathrm{~mm}$ NMR tube. A $400 \mathrm{MHz}$ FoodScreener ${ }^{\mathrm{TM}}$ spectrometer equipped with a BBI probe head with $\mathrm{z}$ gradients was used to acquire the spectra (Bruker Biospin) with a spectral width of $20.458 \mathrm{ppm}$. All samples were handled with the IconNMR and TopSpin 3.5 software. A 1D-NOESY-experiment (noesyggpr1d) was performed with an acquisition time of $4 \mathrm{~s}$ and 32 scans. The excitation pulse was determined before each measurement and the temperature was set to $300 \mathrm{~K}$. The receiver gain was set to a constant value of 32. An exponential window function with an LB of 0.3 was applied during automatic processing. Spectra were referenced to the signal of the internal standard 3-(trimethylsilyl)propanoic acid- $d_{4}$ sodium salt (TSP, $\delta=0 \mathrm{ppm}$ ). To ensure the qualitative comparability of the barley flour extracts, the recovery rate of at least $95 \%$ was determined using the signal of the compound betaine, which was found to be a promising marker for drought response of barley in the course of this study, after double extraction and measurement of a representative sample.

\subsection{Data Preprocessing and Statistical Analysis}

Plots for temperature and precipitation data were done in $\mathrm{R}$ version 3.5.3 using additional packages (ggplot2, ggridges, RColorBrewer). Maps displaying the aridity index grids with a spatial resolution of $1 \mathrm{~km} \times 1 \mathrm{~km}$ were reproduced graphically in the opensource software QGIS version 3.1 (Quantum Geographic Information System). Univariate statistical analysis of isotope data was also conducted in the computing environment $R$. As the assumptions for the use of a parametric test were not met, differences between groups were evaluated by a non-parametric two-sided Mann-Whitney-Wilcoxon test $(\alpha=0.05)$. Chemometric analysis (Kruskal-Wallis test, PCA) of FT-NIR spectra and combined data were performed in MATLAB (Version R2019a, TheMathWorks, Natick, MA, USA). Dimensionality reduction was achieved by splitting the FT-NIR-spectra into bins. Binning (also called bucketing) is a very common pre-processing step for spectral data, that often contain thousands of data points/variables. To ease statistical analysis, the number of variables is reduced by dividing each spectrum into for example equidistant (uniform) so-called bins/buckets and calculating the integral (total area within each bucket) of each bin. In our particular case, each FT-NIR spectrum was divided into 300 equidistant regions in the range between 11,000 and $4000 \mathrm{~cm}^{-1}$. Afterwards, the IRMS variables $\left(\delta^{13} \mathrm{C}, \delta^{15} \mathrm{~N}\right.$, $\delta^{18} \mathrm{O}$ ) were attached to the data set. Feature selection was performed for combined data, extracting the 50 most relevant variables based on ranked class-related variance using a Kruskal-Wallis test. Specifically, the test statistic ( $H$ statistic) of the Kruskal-Wallis test was calculated and used as a filter score, where higher values of the test statistic indicate that the values of the corresponding variable differ more between the classes. Subsequently, the test statistic values were sorted from the highest value to the lowest value to reveal the most relevant variables. Even if statistical approaches are sophisticated, they should not be blindly relied upon. For this reason, we looked at the extracted variables manually to verify that they indeed belong to meaningful spectral regions rather than, e.g., noise. Here, all of the 50 extracted variables were found to be relevant, hence they were used for further statistical analysis. Selected features were then autoscaled (mean-centering followed by division of each column/variable by the standard deviation of that column) and processed using principal component analysis (PCA), to obtain an impression of the differences between spectra among harvest years. As PCA is an exploratory technique rather than a classification technique, we defined a criterium based on which a sample is assigned to a class. Here, we have classified the observations according to their position in the PCA score subspace by defining a threshold based on Euclidean distance to the calculated center of each group at a $95 \%$ confidence level ( $\alpha=5 \%$ ). Using this classification technique, model validation using Monte Carlo cross-validation was performed. Specifically, 100 random models were generated with $90 \%$ of the data set as training data and the remaining $10 \%$ as test set. 


\section{Results and Discussion}

\subsection{Weather at the Sampling Site Differed between 2017 and 2018}

Total precipitation at the sampling site in 2017 was $573.9 \mathrm{~L} / \mathrm{m}^{2}$, which corresponds to $106 \%$ of the mean of the 30-year reference period (1981-2010). In comparison, total precipitation in 2018 was $70 \%$ of the mean of the reference period with a total of $377.1 \mathrm{~L} / \mathrm{m}^{2}$. During the three summer months (June-August), the sum of rainfall was $285.1 \mathrm{~L} / \mathrm{m}^{2}$ $(155 \%)$ in 2017 , while in 2018 , only $77 \mathrm{~L} / \mathrm{m}^{2}$ were recorded, meeting $42 \%$ of the reference period mean (Figure 1a). In addition, the 2018 summer months had 48 days with maximum temperatures above $25^{\circ} \mathrm{C}$ (2017: 28 days), which very likely led to co-occurring heat and drought stress (Figure 1b).

$\mathbf{a}$

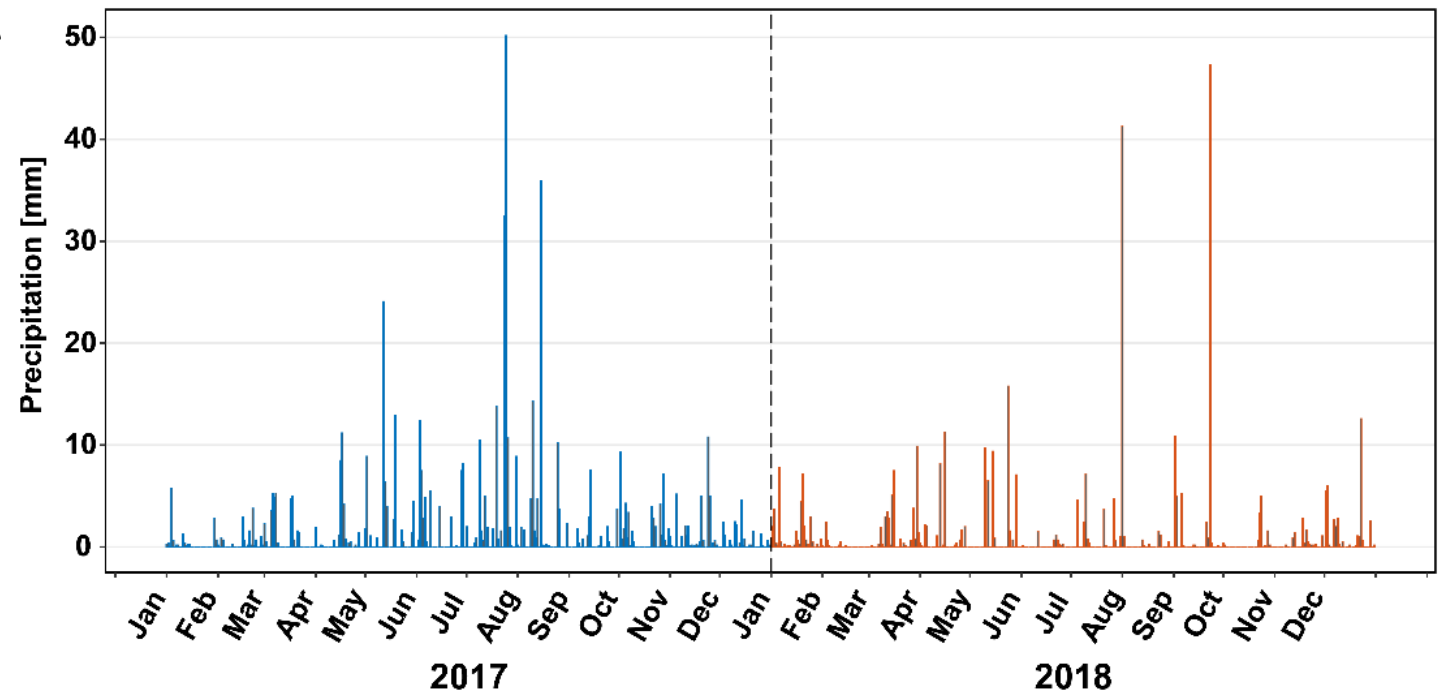

b

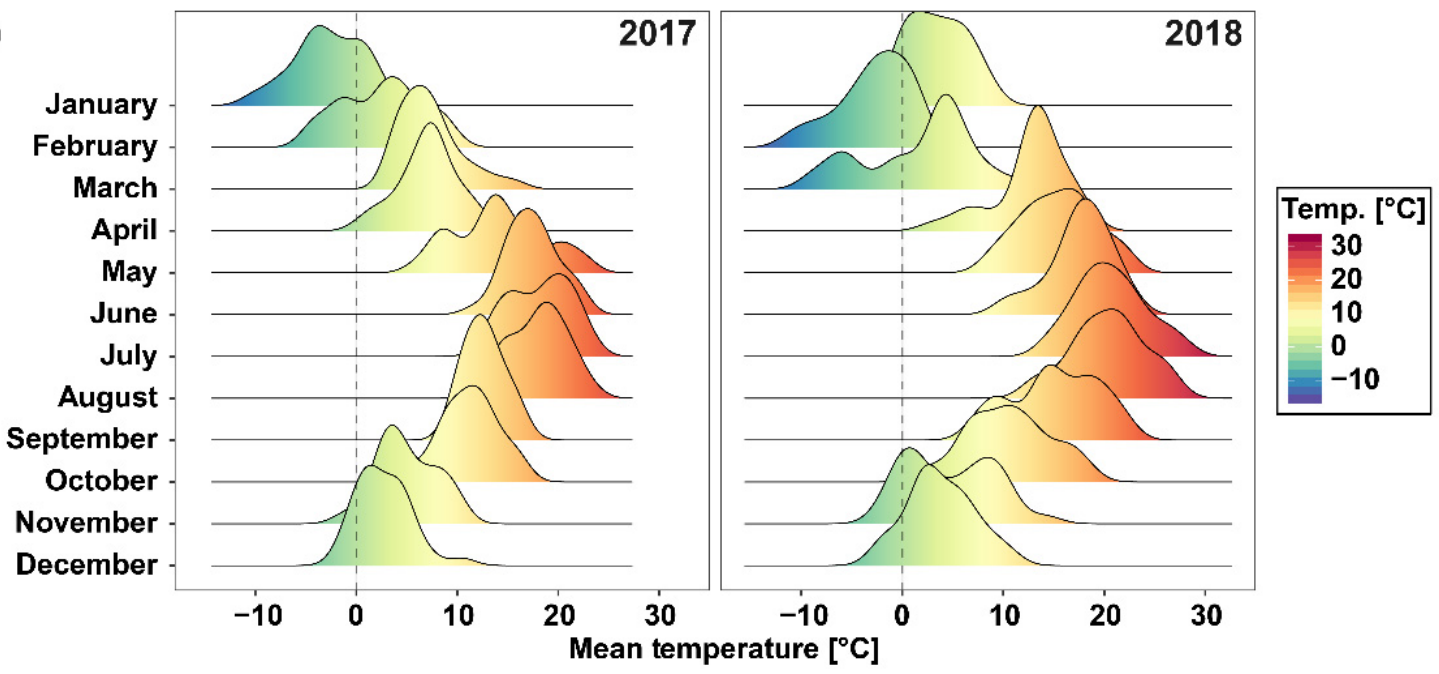

Figure 1. Precipitation and temperature at the sampling site. (a) The graph displays the daily precipitation totals (in $\mathrm{mm}$ ) at the sampling site for the crop years 2017 (blue) and 2018 (red). (b) Density plots show the distribution of daily average air temperatures (in ${ }^{\circ} \mathrm{C}$ ) for the crop years 2017 (left) and 2018 (right). Raw data were retrieved from the weather station (Erfurt-Weimar, German Meteorological Service) with the closest proximity to the sample origin.

Recent findings showed that most barley varieties are particularly sensitive to a combination of these stresses in comparison to heat or drought individually $[14,15]$. Both precipitation and temperature are included in the calculation of the De Martonne's aridity index $\left(I_{D M}\right)$, which was plotted on a map of Germany. Based on the classes of this frequently 
used index, the barley experienced humid to Mediterranean ( $\left.\mathrm{I}_{\mathrm{DM}} \leq 30\right)$ conditions in 2017. In contrast, the year 2018 in the region the samples were sourced was characterized by semi-dry to dry conditions ( $\left.\mathrm{I}_{\mathrm{DM}} \leq 20\right)$ [9] (Figure 2).
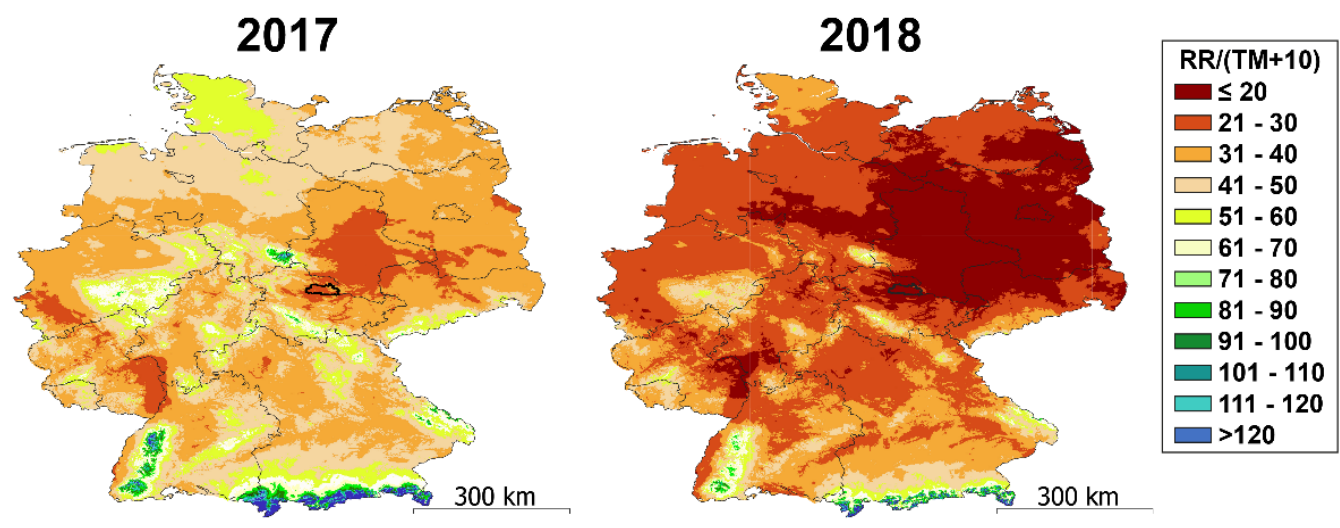

Figure 2. Comparison of the aridity in Germany. Maps show the spatial variation in annual drought index (De Martonne aridity index, $\mathrm{I}_{\mathrm{DM}}$ ) for Germany in the years 2017 (left) and 2018 (right) and the map scale. All values are calculated using the formula: $\mathrm{RR} /(\mathrm{TM}+10)$, where $\mathrm{RR}$ is the annual sum of precipitation (in $\mathrm{mm}$ ) and $\mathrm{TM}$ is the annual mean air temperature (in ${ }^{\circ} \mathrm{C}$ ). Lower index values refer to more pronounced aridity at respective location. The sample origin is highlighted with a thick line and shows index values below 30 in 2017 (humid to Mediterranean) and values below 20 in 2018 (semi-dry to dry).

\subsection{Stable Isotope Abundances Indicate Severe Drought Stress}

Carbon isotope abundances of all analyzed barley samples ranged from $-24.5 \%$ to $-27.6 \%$ with a mean of $-26.3 \%$, which perfectly fits the typical average ratio for the $C_{3}$ crop barley of $-25.9 \pm 0.7 \%$ [16]. Samples from the harvest year 2018 showed significantly less negative $\delta^{13} \mathrm{C}$ values for both Quench (Mdn, $\mathrm{N}_{2017}=-27.1 \%, n=19$; Mdn, $\left.\mathrm{N}_{2018}=-25.2 \%, n=20 ; \mathrm{U}=0, p<0.0001\right)$ and Steffi (Mdn, $\mathrm{N}_{2017}=-26.7 \%, n=$ 22; $\mathrm{Mdn}, \mathrm{N}_{2018}=-26.0 \%, n=25 ; \mathrm{U}=52.5, p<0.0001$ ) compared to samples from 2017 with a more pronounced difference for the Quench variety. The results match the values of studies from Ferrio et al., who found less negative $\delta^{13} \mathrm{C}$ values for bread wheat kernels grown under increased drought stress [17]. Between the two trials that varied the most in water availability, they observed a difference in carbon isotope composition of $2.2 \%$. The less negative values in kernels grown under heavy drought stress match our expectations as the relationship between water status and the carbon isotopic composition of plants and the underlying mechanism are well researched [18]. During assimilation of $\mathrm{CO}_{2}$, plants utilizing the $\mathrm{C}_{3}$ photosynthetic pathway (e.g., barley) discriminate against the heavy isotope of carbon $\left({ }^{13} \mathrm{C}\right)$. Under normal conditions, the $\mathrm{CO}_{2}$-fixing enzyme ribulose 1,5 bisphosphate carboxylase/oxygenase (RubisCO) favors the light ${ }^{12} \mathrm{CO}_{2}$. Stomatal closure in response to drought stress reduces water loss caused by transpiration but also leads to $\mathrm{CO}_{2}$ being 'trapped' inside the leaf's internal air spaces. The closed stomata force the enzyme to process more of the heavy ${ }^{13} \mathrm{CO}_{2}$, as the trapped $\mathrm{CO}_{2}$ is recycled $[19,20]$. The resulting change in isotopic composition of the biomass can be detected in various parts of crops but appears to be most pronounced in mature grains, as they might serve as a sink for different photosynthetic plant organs [21]. Compared to Quench, which is a high-yielding barley cultivar, Steffi is a rather old and less cultivated variety for malting. Therefore, differences in genotype and reaction to drought might have attributed to the more pronounced difference in ${ }^{13} \mathrm{C}$ abundance for Quench (Figure 3a,d) [22]. 

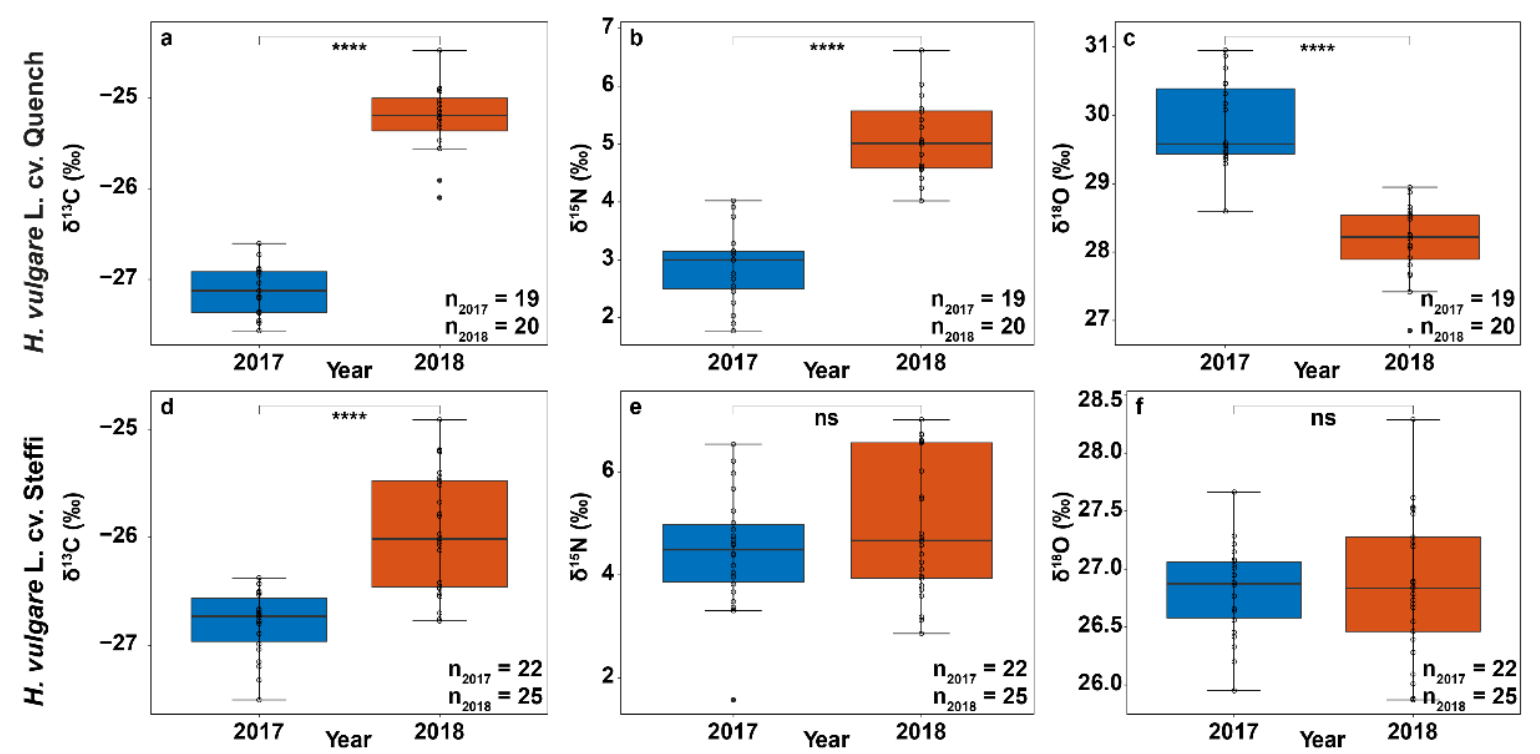

Figure 3. Natural stable isotope abundances of the analyzed spring barley samples. Box and whisker plot graphs with interquartile ranges, medians, error bars (non-outlier minimum and maximum) and results of the Mann-Whitney-Wilcoxon test on the isotopic values $\left(\delta^{13} \mathrm{C}, \delta^{15} \mathrm{~N}, \delta^{18} \mathrm{O}\right)$ of spring barley samples from the two varieties (a-c) Quench and (d-f) Steffi. Samples are grouped based on the crop years 2017 (blue) and 2018 (red). Highly significant differences $(p<0.0001)$ are highlighted with four stars $\left.{ }^{* * * *}\right)$, while non-significant differences are marked with 'ns'. Outliers are denoted as filled circles.

In fact, there is growing evidence that some barley genotypes, which carry more desirable wild-type traits, have a higher abiotic stress tolerance to environmental factors such as drought and heat, thus raising interest in targeted breeding of cultivated barley, especially in view of the challenges posed by climate change $[23,24]$. The reported $\mathrm{N}$ isotopic compositions showed significant interannual differences for the Quench variety (Mdn, $\mathrm{N}_{2017}=3.0 \%, n=19 ; \mathrm{Mdn}, \mathrm{N}_{2018}=5.0 \%, n=20 ; \mathrm{U}=1, p<0.0001$ ) with a higher $\delta^{15} \mathrm{~N}$ in the dry year 2018, while no difference was found for Steffi (Mdn, $\mathrm{N}_{2017}=4.5 \%, n=22$; Mdn, $\mathrm{N}_{2018}=4.7 \%, n=25 ; \mathrm{U}=229.5, p>0.05$ ) (Figure 3). The connection between plant $\delta^{15} \mathrm{~N}$ values and aridity are not straightforward, as multiple factors such as microorganism activity, $\mathrm{N}$ source, and plant metabolism influence the signature. The observed increase in $\delta^{15} \mathrm{~N}$ for Quench might be attributed to differences in agricultural practice, response of nitrate reductase activity to drought or due to limited uptake and transfer of $\mathrm{N}$ to the upper plant parts [25]. Apart from the information that the barley comes from conventional cultivation, details on fertilization are missing, which makes interpretation of the $\delta^{15} \mathrm{~N}$ values rather challenging. At the same time, such obstacles reflect the intention of the study, namely to create real conditions that can be transferred to the market. In our approach, these uncertainties can, to some extent, be compensated by using several measurement techniques for a more holistic point of view. As for nitrogen isotope composition, $\delta^{18} \mathrm{O}$ was significantly different between the two harvest years for the variety Quench (Mdn, $\mathrm{N}_{2017}=29.6 \%, n=19 ; \mathrm{Mdn}, \mathrm{N}_{2018}=28.2 \%$ o, $\left.n=20 ; \mathrm{U}=376, p<0.0001\right)$ with lower $\delta^{18} \mathrm{O}$ values in 2018, while no significant difference was found for the Steffi variety (Mdn, $\mathrm{N}_{2017}$ $=26.9 \%, n=22 ; \mathrm{Mdn}, \mathrm{N}_{2018}=26.8 \%, n=25 ; \mathrm{U}=270, p>0.05$ ) (Figure 3). A missing interannual difference in $\delta^{18} \mathrm{O}$ values is rather unexpected as similar to $\delta^{13} \mathrm{C}$ values, oxygen isotopic signatures are expected to increase with higher evaporative demand and lower stomatal conductance [17]. However, several studies suggest that there is a lack of a clear relationship in grains compared to, e.g., leaf material or whole plant material. For spring wheat, Barbour, Fischer, Sayre, \& Farquhar reported a significant positive correlation of $\delta^{13} \mathrm{C}$ and $\delta^{18} \mathrm{O}$ in flag leaves, but the relationship was less clear in grains [26]. We conclude, while grain $\delta^{13} \mathrm{C}$ seems to be a good marker for water status during grain filling, other factors seem to specifically affect $\delta^{18} \mathrm{O}$. The signal could be dominated by variations in 
$\delta^{18} \mathrm{O}$ signature of the source water, or it could be influenced by biochemical fractionation during synthesis of grain organic matter from remobilized assimilates [17]. Considering the heavy drought in 2018, a higher contribution of pre-anthesis reserves to grain filling is very likely, which would lead to lower $\delta^{18} \mathrm{O}$ values $[27,28]$.

\subsection{FT-NIR Spectra Show Additional Drought-Related Differences}

For visual presentation of the differences in the FT-NIR spectra between the samples from the two harvest years, average spectra were calculated, and signal assignments of fundamental regions were included (Figure 4).
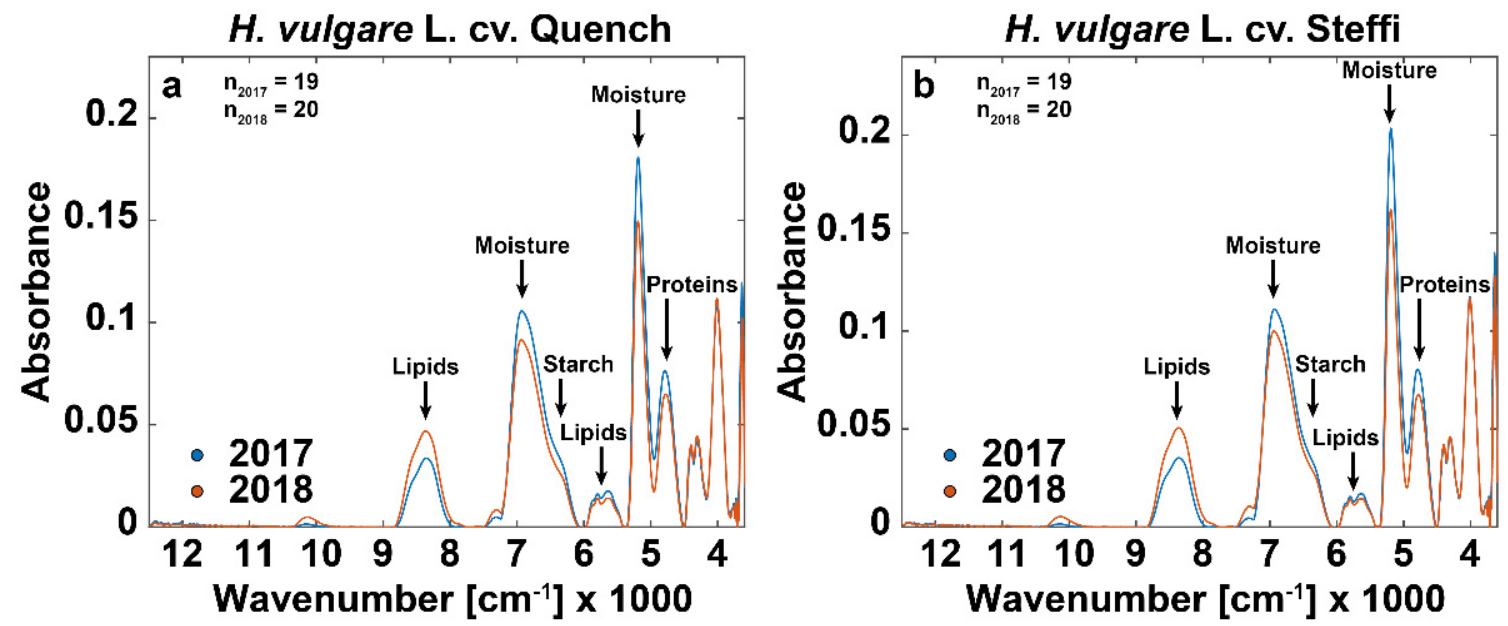

Figure 4. Comparison of spring barley kernel FT-NIR spectra. Figures display baseline-corrected average FT-NIR spectra (4000 to 12,000 $\mathrm{cm}^{-1}$ ) for whole kernels of the spring barley varieties (a) Quench and (b) Steffi. Samples are grouped based on the crop years 2017 (blue) and 2018 (red). Assignments of relevant spectral bands are indicated at the respective absorbance peak.

It is noteworthy that the spectra of both cultivars show the same changes for the year 2018, indicating similar metabolite responses to drought stress. The absorbance peak at around $8264 \mathrm{~cm}^{-1}(1200 \mathrm{~nm})$ was related to the second overtone of C-H stretching, whereas the absorbance peak at $5665 \mathrm{~cm}^{-1}(1765 \mathrm{~nm})$ was related to the first harmonic of $\mathrm{C}-\mathrm{H}$ stretching. Both peaks are attributed with lipids and showed noteworthy differences between the harvest years, which is consistent with results from a study using GC/MSbased metabolite profiling [29-31]. Further, we observed two absorbance bands with outstanding separation between harvest years that were linked to moisture at around 6800 $\mathrm{cm}^{-1}$ (1470 nm, first overtone of O-H stretching) [29,32,33] and $5170 \mathrm{~cm}^{-1}(1934 \mathrm{~nm}, \mathrm{O}-\mathrm{H}$ stretching) $[29,30,32,34,35]$. Based on a nationwide report by the Federal Ministry of Food and Agriculture, in 2018 all cereals, including barley, showed significant reduction in average moisture content in comparison to the previous year, which fits our observations [36]. The absorbance band around $6300 \mathrm{~cm}^{-1}(1587 \mathrm{~nm}$, first overtone of O-H stretching) is a bit lower for the grain samples from 2018 and was associated with starch, whose synthesis is known to be hindered by drought stress [29,30,34,37]. Finally, we could observe differences between harvest years at the absorbance peak around $4854 \mathrm{~cm}^{-1}(2060 \mathrm{~nm})$. The band is associated with a combination of $\mathrm{C}-\mathrm{H}$ stretching, $\mathrm{N}-\mathrm{H}$ stretching, and $\mathrm{O}-\mathrm{H}$ stretching and is related to variation in protein characteristics potentially attributed to osmotic adjustments $[29,31,32,34]$. 


\subsection{Data Fusion Enables Differentiation of Barley Harvest Years}

In a next step, we statistically evaluated the FT-NIR spectra and data produced by IRMS, using Kruskal-Wallis tests and principal component analysis (PCA). The created models achieved $100 \%$ correct classification of harvest years for both barley varieties (Figure 5).
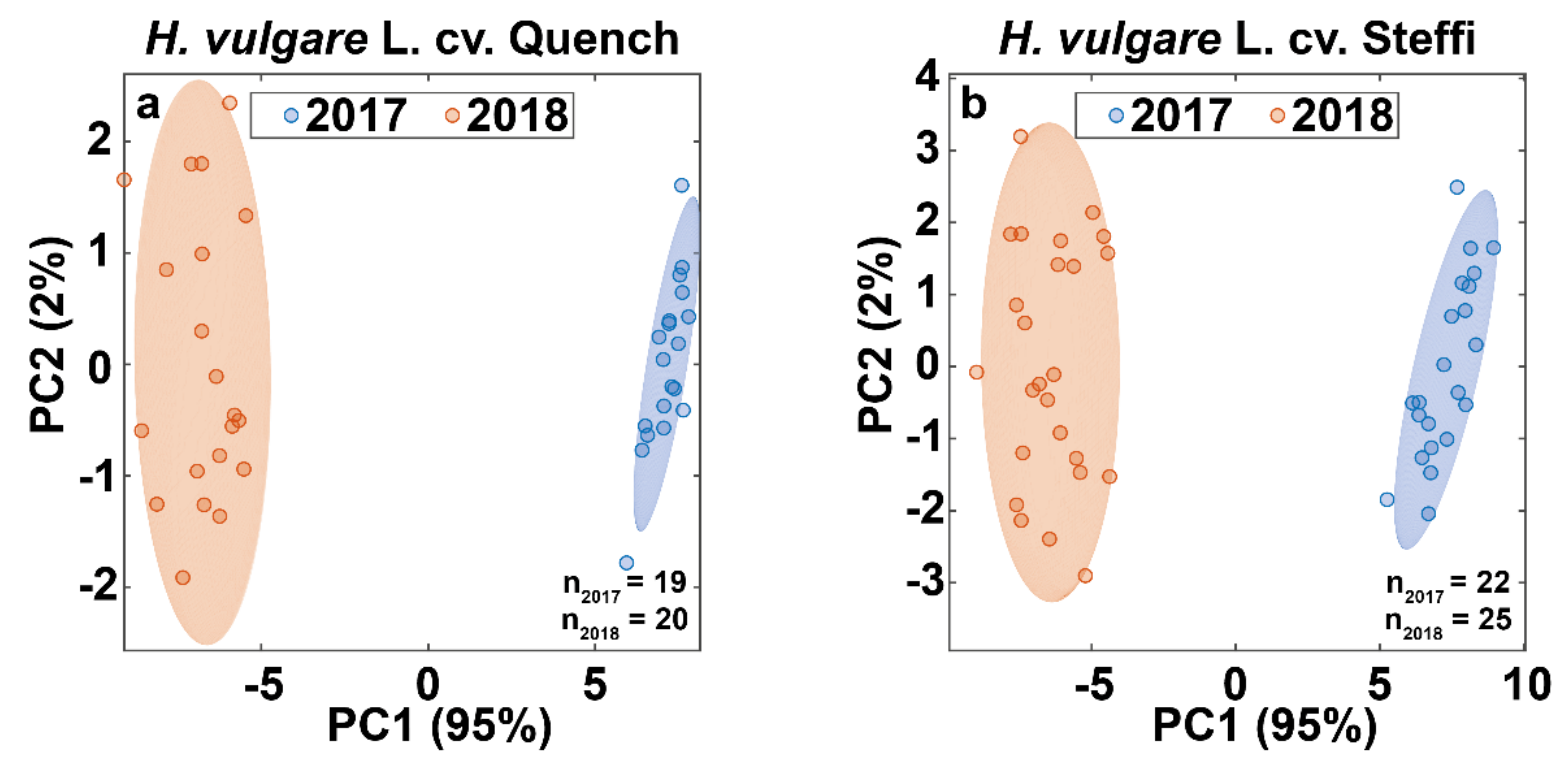

Figure 5. Chemometric analysis of combined FT-NIR and IRMS data. Score plots including 95\% confidence ellipses of the first two principal components from the PCA of fused data (FT-NIR and IRMS). Plots are displayed for the two spring barley varieties (a) Quench and (b) Steffi, and the samples are colored by the crop years 2017 (blue) and 2018 (red). For each principal component, the respective percentage of variance explained is given in the axis label.

To gain insight into which of the included variables contributed most to the separation, we ranked them by importance using a Kruskal-Wallis test. We found that the abundance peak at around $8264 \mathrm{~cm}^{-1}(1200 \mathrm{~nm})$ was the most important, followed by the absorbance bands around $4854 \mathrm{~cm}^{-1}(2060 \mathrm{~nm}), 5170 \mathrm{~cm}^{-1}(1934 \mathrm{~nm}), 5665 \mathrm{~cm}^{-1}(1765 \mathrm{~nm})$, and $6800 \mathrm{~cm}^{-1}(1470 \mathrm{~nm})$. This is consistent with findings from the literature, which state that the composition and content of lipids and proteins in barley change significantly under stress conditions such as heat and drought $[24,38]$. Interestingly, in the statistical analysis of the Quench variety, the carbon isotopic composition appeared among the most important variables for the separation of crop years, but not for the Steffi variety. Given that the difference in the natural ${ }^{13} \mathrm{C}$ abundance is a marker for water-use efficiency, there is growing evidence that the old Steffi variety is better adapted to drought [20].

\section{5. ${ }^{1} \mathrm{H}$-NMR Confirms Observations by Means of the Marker Betaine}

Finally, we used ${ }^{1} \mathrm{H}-\mathrm{NMR}$ spectra of sample extracts that serve as quantitative metabolite fingerprints. These can not only be analyzed in a non-targeted approach, but also in high-resolution identification of molecular markers. In our case, we focused on plant physiological markers such as osmolytes, which might indicate a plant's response to stress conditions. A direct comparison of the ${ }^{1} \mathrm{H}-\mathrm{NMR}$ spectra from the two investigated harvest years revealed a significantly increased signal intensity at $3.255 \mathrm{ppm}$ chemical shift in all samples from the year 2018. Importantly, this is regardless of which of the two barley varieties was considered (Figure 6). 

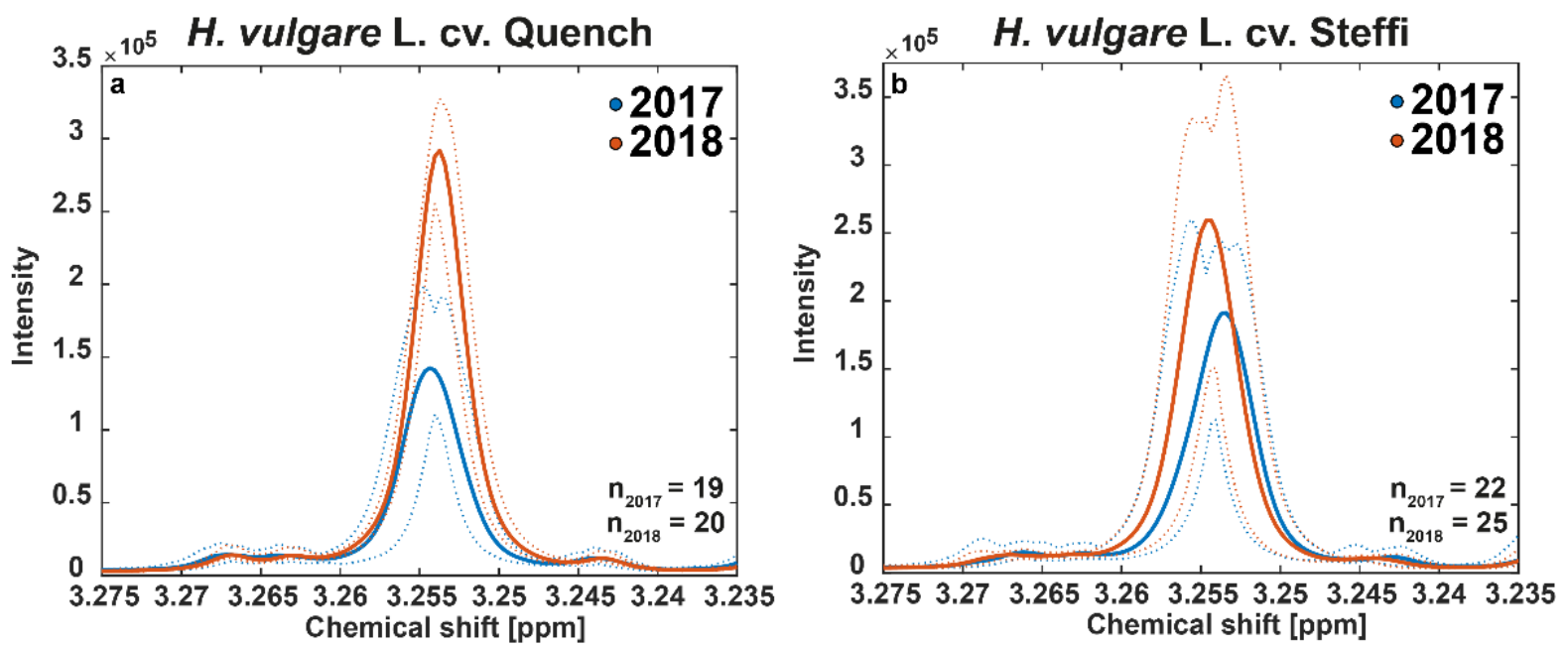

Figure 6. Comparison of the content of the plant-physiological marker betaine. Plots show the ${ }^{1} \mathrm{H}-\mathrm{NMR}$ spectra region (3.275-3.235 ppm), including the signal of betaine at 3.255 ppm chemical shift. The two spring barley varieties (a) Quench and (b) Steffi were analyzed as wholemeal flour extracts. Average spectra are displayed as solid lines and the 95\% confidence intervals are represented as dotted lines. Samples are colored by the harvest years 2017 (blue) and 2018 (red). Note that there are minor differences in chemical shift due to slight variations in the sample conditions, which lead to apparent multiplets when the included spectra are averaged. This also creates multiple maxima for the confidence intervals (dotted lines). However, the betaine signal at $3.255 \mathrm{ppm}$ is a singlet.

A comparison with common databases and subsequent spiking experiments for confirmation with the pure substance revealed that the signal refers to betaine (trimethylglycine). Accumulation of this methyl donor is a well-known and critical response of barley to environmental stress such as drought [39]. We would like to mention here that for the purposes of this paper, we consider only this section of the spectrum, as it provides the marker for drought stress and thus the biological background. However, it can be assumed that an elaborate statistical analysis of the complete NMR spectra could reveal other exciting relationships. On a molecular level, the connection between drought stress and betaine accumulation can be explained by the function of the plant hormone abscisic acid (ABA), which not only induces stomatal closure to prevent water loss but was also found to increase expression of betaine aldehyde dehydrogenase (BADH), catalyzing the last step in the synthesis of betaine [40]. The relationship is underpinned by the fractionation we observed for the carbon isotopic composition, which is caused by stomata regulation. Although this important plant physiological process has often been demonstrated by experiments with whole plants or leaves, elevated concentrations of betaine resulting from high temperatures and drought have also been observed in studies with grains of wheat and barley [31,41]. In respective results, there were clear differences between individual genotypes, on the one hand in the basic content of betaine, but also in the degree of accumulation in response to stress. This might explain the difference observed between the two investigated varieties, with the old cultivar once more showing a milder response, possibly due to a higher tolerance to environmental stress.

\section{Conclusions}

Global warming creates circumstances for the agricultural sector that require rapid action and unprecedented scientific approaches. A central component is the transfer of knowledge from controlled field experiments to real market samples. Our results show that spring barley undergoes noticeable changes in its chemical composition in an extremely dry and hot year like 2018, enabling a solid discriminability from samples of 2017. The significantly less negative $\delta^{13} \mathrm{C}$ values for both analyzed varieties proved to be a suitable marker for water status during grain filling. Furthermore, FT-NIR and ${ }^{1} \mathrm{H}-\mathrm{NMR}$ spectra showed significant differences between the two harvest years, especially in the absorbance 
bands related to lipids and proteins and the stress marker betaine. All observed chemical changes could be explained and linked by means of plant physiology, which is an integral part of authenticity testing of plant-based foods. Furthermore, the weaker stress response of the old cultivar "Steffi" has shown that the data obtained can also be transferred to targeted breeding of varieties that tolerate future climate conditions. We are convinced that additional research on our initial findings will show the broad applicability to unknown systems and will be the go-to practice in agricultural science.

Author Contributions: Conceptualization, S.G.B., G.G., and S.S. (Stephan Schwarzinger); methodology, S.G.B.; software, S.G.B., F.R., S.S. (Stephan Schwarzinger), and P.K.; validation, S.G.B., S.S. (Simon Steidele), and P.K.; formal analysis, S.G.B.; investigation, S.G.B., P.K., S.S., and L.K.; resources, H.W., S.S. (Stephan Schwarzinger), and G.G.; data curation, S.G.B., H.W., F.R., L.K., and P.K.; writingoriginal draft preparation, S.G.B.; writing-review and editing, S.G.B., S.S. (Stephan Schwarzinger), and G.G.; visualization, S.G.B.; supervision, S.S. (Stephan Schwarzinger), G.G., L.K., and H.W.; project administration, S.S. (Stephan Schwarzinger); funding acquisition, S.S. (Stephan Schwarzinger). All authors have read and agreed to the published version of the manuscript.

Funding: The work was supported by funds of the Federal Ministry of Food and Agriculture (BMEL) based on a decision of the Parliament of the Federal Republic of Germany via the Federal Office for Agriculture and Food (BLE) under the innovation support program (Reference number: 2816502414). This publication was funded by the German Research Foundation (DFG) and the University of Bayreuth in the Open Access Publishing funding program.

Data Availability Statement: All weather-related data can be accessed from the Climate Data Center, provided by the German Meteorological Service (https:/ /cdc.dwd.de/portal), https:/ / opendata. dwd.de/climate_environment/CDC/). The MATLAB code used for the chemometric analysis of data is available at the gitlab repository of the co-author Felix Rüll (https: / gitlab.com/FelR/ai-omics). Detailed raw data for IRMS, FT-NIR and ${ }^{1} \mathrm{H}-\mathrm{NMR}$ measurements are available upon request from the corresponding author.

Acknowledgments: First: we would like to thank Paul Rösch (University of Bayreuth) for his great support in the project. We also thank Carina Bauer, Petra Eckert and Christine Tiroch (University of Bayreuth) for performing the stable isotope abundance measurements. Further, we thank Felix Brauer (ALNuMed GmbH, Bayreuth, Germany) for technical assistance with ${ }^{1} \mathrm{H}-\mathrm{NMR}$ analyses and Stephen Strassburg (University of Bayreuth) for comments on language. Special thanks to all AgrOr-project partners who made this work possible.

Conflicts of Interest: S.S. (Stephan Schwarzinger) is co-founder and former CEO (approved secondary employment) of the ALNuMed GmbH (Bayreuth, Germany). P.K. and L.K. are former employees of the ALNuMed GmbH (Bayreuth, Germany). H.W. is employed by the IREKS GmbH (Kulmbach, Germany). All authors declare no conflicts of interest.

\section{References}

1. Sun, Q.; Gilgen, A.K.; Signarbieux, C.; Klaus, V.H.; Buchmann, N. Cropping Systems Alter Hydraulic Traits of Barley but not Pea Grown in Mixture. Plant Cell Environ. 2021, 1-13. [CrossRef]

2. Trnka, M.; Rötter, R.P.; Ruiz-Ramos, M.; Kersebaum, K.C.; Olesen, J.E.; Žalud, Z.; Semenov, M.A. Adverse weather conditions for European wheat production will become more frequent with climate change. Nat. Clim. Chang. 2014, 4, 637-643. [CrossRef]

3. Giraldo, P.; Benavente, E.; Manzano-Agugliaro, F.; Gimenez, E. Worldwide research trends on wheat and barley: A bibliometric comparative analysis. Agronomy 2019, 9, 352. [CrossRef]

4. Paynter, B.H.; Young, K.J. Grain and malting quality in two-row spring barley are influenced by grain filling moisture. Aust. J. Agric. Res. 2004, 55, 539-550. [CrossRef]

5. Federal Ministry of Food and Agriculture (BMEL)—Erntebericht 2018. Available online: https://www.bmel.de/SharedDocs/ Downloads/DE/_Landwirtschaft/Pflanzenbau/Ernte-Bericht/ernte-2018.pdf;jsessionid=E982D6918788080F847DB05B67B2 7E07.live921?_blob=publicationFile\&v=2 (accessed on 23 May 2021).

6. Heinrich Durst Malzfabriken GmbH \& Co. KG. Requirements and Conditions of Barley Deliveries to Durst Malz-Crop 2020. Available online: http://www.durst-malz.de/uploads/media/Requirements_Crop_20_EN.pdf (accessed on 23 May 2021).

7. Xie, W.; Xiong, W.; Pan, J.; Ali, T.; Cui, Q.; Guan, D.; Meng, J.; Mueller, N.D.; Lin, E.; Davis, S.J. Decreases in global beer supply due to extreme drought and heat. Nat. Plants 2018, 4, 964-973. [CrossRef] [PubMed] 
8. Kaspar, F.; Müller-Westermeier, G.; Penda, E.; Mächel, H.; Zimmermann, K.; Kaiser-Weiss, A.; Deutschländer, T. Monitoring of climate change in Germany-data, products and services of Germany's National Climate Data Centre. Adv. Sci. Res. 2013, 10, 99-106. [CrossRef]

9. de Martonne, E. Une nouvelle function climatologique: L'indice d'aridité. Meteorologie 1926, 2, 449-458.

10. Bidartondo, M.I.; Burghardt, B.; Gebauer, G.; Bruns, T.D.; Read, D.J. Changing partners in the dark: Isotopic and molecular evidence of ectomycorrhizal liaisons between forest orchids and trees. Proc. R. Soc. B Biol. Sci. 2004, 271, 1799-1806. [CrossRef]

11. Gebauer, G.; Preiss, K.; Gebauer, A.C. Partial mycoheterotrophy is more widespread among orchids than previously assumed. New Phytol. 2016, 211, 11-15. [CrossRef]

12. Gebauer, G.; Schulze, E.D. Carbon and nitrogen isotope ratios in different compartments of a healthy and a declining Picea abies forest in the Fichtelgebirge, NE Bavaria. Oecologia 1991, 87, 198-207. [CrossRef]

13. Godelmann, R.; Fang, F.; Humpfer, E.; Schütz, B.; Bansbach, M.; Schäfer, H.; Spraul, M. Targeted and nontargeted wine analysis by ${ }^{1} \mathrm{H}$ NMR spectroscopy combined with multivariate statistical analysis. Differentiation of important parameters: Grape variety, geographical origin, year of vintage. J. Agric. Food Chem. 2013, 61, 5610-5619. [CrossRef] [PubMed]

14. Mahalingam, R. Phenotypic, physiological and malt quality analyses of US barley varieties subjected to short periods of heat and drought stress. J. Cereal Sci. 2017, 76, 199-205. [CrossRef]

15. Mahalingam, R.; Bregitzer, P. Impact on physiology and malting quality of barley exposed to heat, drought and their combination during different growth stages under controlled environment. Physiol. Plant. 2019, 165, 277-289. [CrossRef]

16. Brooks, J.R.; Buchmann, N.; Phillips, S.; Ehleringer, B.; Evans, R.D.; Lott, M.; Martinelli, L.A.; Pockman, W.T.; Sandquist, D.; Sparks, J.P.; et al. Heavy and light beer: A carbon isotope approach to detect $\mathrm{C}_{4}$ carbon in beers of different origins, styles, and prices. J. Agric. Food Chem. 2002, 50, 6413-6418. [CrossRef]

17. Ferrio, J.P.; Mateo, M.A.; Bort, J.; Abdalla, O.; Voltas, J.; Araus, J.L. Relationships of grain $\delta^{13} \mathrm{C}$ and $\delta^{18} \mathrm{O}$ with wheat phenology and yield under water-limited conditions. Ann. Appl. Biol. 2007, 150, 207-215. [CrossRef]

18. Hubick, K.; Farquhar, G. Carbon isotope discrimination and the ratio of carbon gained to water lost in barley cultivars. Plant Cell Environ. 1989, 12, 795-804. [CrossRef]

19. Farquhar, G.D.; O'Leary, M.H.; Berry, J.A. On the relationship between carbon isotope discrimination and the intercellular carbon dioxide concentration in leaves. Aust. J. Plant Physiol. 1982, 9, 121-137. [CrossRef]

20. Farquhar, G.D.; Richards, R.A. Isotopic composition of plant carbon correlates with water-use efficiency of wheat genotypes. Aust. J. Plant Physiol. 1984, 11, 539-552. [CrossRef]

21. Sánchez-Díaz, M.; García, J.L.; Antolín, M.C.; Araus, J.L. Effects of soil drought and atmospheric humidity on yield, gas exchange, and stable carbon isotope composition of barley. Photosynthetica 2002, 40, 415-421. [CrossRef]

22. Liu, H.; Guo, B.; Wei, Y.; Wei, S.; Ma, Y.; Zhang, W. Effects of region, genotype, harvest year and their interactions on $\delta^{13} \mathrm{C}, \delta^{15} \mathrm{~N}$ and $\delta \mathrm{D}$ in wheat kernels. Food Chem. 2015, 171, 56-61. [CrossRef]

23. Ivandic, V.; Hackett, C.A.; Zhang, Z.J.; Staub, J.E.; Nevo, E.; Thomas WT, B.; Forster, B.P. Phenotypic responses of wild barley to experimentally imposed water stress. J. Exp. Bot. 2000, 51, 2021-2029. [CrossRef]

24. Wu, X.; Cai, K.; Zhang, G.; Zeng, F. Metabolite profiling of barley grains subjected to water stress: To explain the genotypic difference in drought-induced impacts on malting quality. Front. Plant Sci. 2017, 8, 1547. [CrossRef]

25. Lopes, M.S.; Araus, J.L. Nitrogen source and water regime effects on durum wheat photosynthesis and stable carbon and nitrogen isotope composition. Physiol. Plant. 2006, 126, 435-445. [CrossRef]

26. Barbour, M.M.; Fischer, R.A.; Sayre, K.D.; Farquhar, G.D. Oxygen isotope ratio of leaf and grain material correlates with stomatal conductance and grain yield in irrigated wheat. Aust. J. Plant Physiol. 2000, 27, 625-637. [CrossRef]

27. Flood, R.G.; Martin, P.J.; Gardner, W.K. Dry matter accumulation and partitioning and its relationship to grain yield in wheat. Aust. J. Exp. Agric. 1995, 35, 495-502. [CrossRef]

28. Slafer, G.A.; Satorre, E.H.; Andrade, F.H. Increases in grain yield in bread wheat from breeding and associated physiological changes. In Genetic Improvement of Field Crops, 1st ed.; Slafer, G.A., Ed.; Marcel Dekker Inc.: New York, NY, USA, $1994 ;$ pp. 1-54.

29. De Girolamo, A.; Cortese, M.; Cervellieri, S.; Lippolis, V.; Pascale, M.; Logrieco, A.F.; Suman, M. Tracing the geographical origin of durum wheat by FT-NIR spectroscopy. Foods 2019, 8, 450. [CrossRef]

30. Shenk, J.S.; Workman, J.J.; Westerhaus, M.O. Application of NIR spectroscopy to agricultural products. In Handbook of Near-Infrared Analysis, 3rd ed.; Burns, D.A., Ciurczak, E.W., Eds.; Marcel Dekker Inc.: New York, NY, USA, 2001; pp. 419-474.

31. Wenzel, A.; Frank, T.; Reichenberger, G.; Herz, M.; Engel, K.H. Impact of induced drought stress on the metabolite profiles of barley grain. Metabolomics 2015, 11, 454-467. [CrossRef]

32. Cozzolino, D.; Roumeliotis, S.; Eglinton, J. Exploring the use of near infrared (NIR) reflectance spectroscopy to predict starch pasting properties in whole grain barley. Food Biophys. 2013, 8, 256-261. [CrossRef]

33. Zhao, H.; Guo, B.; Wei, Y.; Zhang, B. Effects of grown origin, genotype, harvest year, and their interactions of wheat kernels on near infrared spectral fingerprints for geographical traceability. Food Chem. 2014, 152, 316-322. [CrossRef] [PubMed]

34. McGoverin, C.M.; Engelbrecht, P.; Geladi, P.; Manley, M. Characterisation of non-viable whole barley, wheat and sorghum grains using near-infrared hyperspectral data and chemometrics. Anal. Bioanal. Chem. 2011, 401, 2283. [CrossRef] [PubMed]

35. Sohn, M.; Himmelsbach, D.S.; Barton, F.E.; Griffey, C.A.; Brooks, W.; Hicks, K.B. Near-infrared analysis of whole kernel barley: Comparison of three spectrometers. Appl. Spectrosc. 2008, 62, 427-432. [CrossRef] [PubMed] 
36. Federal Ministry of Food and Agriculture (BMEL)—Besondere Ernte- und Qualitätsermittlung 2018. Available online: https: / / www.bmel-statistik.de/fileadmin/daten/EQB-1002000-2018.pdf (accessed on 23 May 2021).

37. Chaves, M.M. Effects of water deficits on carbon assimilation. J. Exp. Bot. 1991, 42, 1-16. [CrossRef]

38. Högy, P.; Poll, C.; Marhan, S.; Kandeler, E.; Fangmeier, A. Impacts of temperature increase and change in precipitation pattern on crop yield and yield quality of barley. Food Chem. 2013, 136, 1470-1477. [CrossRef] [PubMed]

39. Kebede, A.; Kang, M.S.; Bekele, E. Advances in mechanisms of drought tolerance in crops, with emphasis on barley. In Advances in Agronomy; Sparks, D.L., Ed.; Academic Press: London, UK, 2019; Volume 156, pp. 265-314. [CrossRef]

40. Ishitani, M.; Nakamura, T.; Han, S.Y.; Takabe, T. Expression of the betaine aldehyde dehydrogenase gene in barley in response to osmotic stress and abscisic acid. Plant Mol. Biol. 1995, 27, 307-315. [CrossRef] [PubMed]

41. Corol, D.I.; Ravel, C.; Raksegi, M.; Bedo, Z.; Charmet, G.; Beale, M.H.; Shewry, P.R.; Ward, J.L. Effects of genotype and environment on the contents of betaine, choline, and trigonelline in cereal grains. J. Agric. Food Chem. 2012, 60, 5471-5481. [CrossRef] 